\title{
Vittariaceae (Pteridophyta) do Sudeste do Brasil ${ }^{1}$
}

\author{
FABIANA R. NONATO ${ }^{2,4}$ e PAULO G. WINDISCH ${ }^{3}$
}

(recebido: 26 de dezembro de 2002; aceito: 20 de novembro de 2003)

\begin{abstract}
Vittariaceae (Pteridophyta) from southeastern Brazil). A floristic and taxonomic study of the family Vittariaceae in southeastern Brazil is presented. Seven of the ten genera, which comprise this family, are American. Five genera and nine species occur in the studied region: Anetium Splitg. and Hecistopteris J. Sm. with one species each; Polytaenium Desv. with three species; Radiovittaria (Benedict) E.H. Crane and Vittaria Sm. with two species each. Identification keys for genera and species are presented. The studied species are described and illustrated, and taxonomic and ecological commentaries were included.
\end{abstract}

Key words - diversity, ferns, floristics, southeastern Brazil, Vittariaceae

RESUMO - (Vittariaceae (Pteridophyta) do Sudeste do Brasil). Um estudo florístico e taxonômico da família Vittariaceae no Sudeste do Brasil é apresentado. Sete dos dez gêneros que compreendem esta família são americanos. Cinco gêneros e nove espécies ocorrem na região estudada: Anetium Splitg. e Hecistopteris J. Sm., com uma espécie cada; Polytaenium Desv. com três espécies; Radiovittaria (Benedict) E.H. Crane e Vittaria Sm., com duas espécies cada. Foram elaboradas chaves para determinação de gêneros e espécies. As espécies tratadas foram descritas e ilustradas, sendo incluídos comentários taxonômicos e ecológicos.

Palavras-chave - diversidade, florística, samambaias, Sudeste do Brasil, Vittariaceae

\section{Introdução}

A família Vittariaceae apresenta cerca de 100 espécies. São predominantemente epífitas, podendo ocorrer também sobre rochas. A maioria dos seus representantes é facilmente reconhecida pelas frondes inteiras e pendentes, por vezes alcançando mais de um metro de comprimento. Contudo, alguns representantes podem apresentar frondes furcadas com poucos centímetros de comprimento.

A morfologia uniforme e simples exibida pela maioria das espécies oferece poucos caracteres para classificação. A delimitação genérica na família tem variado entre os autores. Copeland (1947) reconheceu nove gêneros, enquanto que Tryon \& Tryon (1982) e Kramer (1990) reconheceram apenas seis. Crane et al. (1995) e Crane (1997), baseados em características moleculares e morfológicas, forneceram a base para

\footnotetext{
1. Parte da Dissertação de Mestrado de F.R. Nonato, desenvolvida no Curso de Pós-graduação em Botânica do Museu Nacional, Universidade Federal do Rio de Janeiro.

2. Universidade Estadual de Feira de Santana, Departamento de Ciências Biológicas, BR 116, km 03, Campus Universitário, 44031-460 Feira de Santana, BA, Brasil.

3. Universidade do Vale do Rio dos Sinos, Programa de Pós-graduação em Biologia, Centro 2, Avenida Unisinos 950, 93022-000 São Leopoldo, RS, Brasil.

4. Autor para correspondência: frnonato@uefs.br
}

uma boa delimitação genérica, apresentando uma circunscrição revisada da família Vittariaceae e reconhecendo dez gêneros monofiléticos.

A família Vittariaceae apresenta distribuição pantropical, estendendo-se até regiões temperadas, com algumas espécies na África do Sul, Japão, Sudeste dos Estados Unidos da América e na Argentina (Kramer 1990). Raros são os trabalhos sobre os representantes do Brasil, principalmente os da região Sudeste. Dentre estes se ressaltam Fée $(1869,1873)$, Baker (1870), Christ (1900), Rosenstock (1904), Brade (1920) e Sehnem (1967).

O presente estudo tem como objetivo realizar o levantamento da família Vittariaceae para a região Sudeste do Brasil, com a elaboração de descrições e chaves de identificação que permitam o reconhecimento de gêneros e espécies, e análise de suas distribuições geográficas.

\section{Material e métodos}

O trabalho foi desenvolvido com base no material dos principais herbários do Sul e Sudeste do Brasil, bem como em dados de campo. O material coletado foi herborizado segundo Windisch (1992) e encontra-se depositado no Herbário do Museu Nacional (R).

O sistema de classificação e descrições das categorias genéricas e infragenéricas segue Crane (1997). A descrição da família foi baseada em Tryon \& Tryon (1982) e Kramer 
(1990). Optou-se pelo uso dos termos "fronde" e "estípite", tal como adotado por Windisch \& Nonato (1999), ao invés dos termos "folha" e "pecíolo", respectivamente.

Foram preparadas ilustrações de caracteres diagnósticos. A distribuição de cada espécie foi elaborada com base no material de herbário e em bibliografia especializada. As siglas dos herbários seguem Holmgren et al. (1990). Os nomes de autores de táxons estão abreviados segundo Pichi-Sermolli (1996).

\section{Resultados e Discussão}

Vittariaceae (C. Presl) Ching, Sunyatsenia 5(4):232. 1940.

Vittariaceae C. Presl, Tent. pterid.:164. 1836, como tribo. Tipo: Vittaria Sm.

Fase esporofítica representada por plantas epífitas, menos freqüentemente rupícolas, raramente terrestres, 2-120 cm compr. Raízes filamentosas a esponjosas, freqüentemente com indumento piloso. Caule protostélico (nas formas menores) ou solenostélico a dictiostélico, com estágios transitórios, reptante a ereto, dorsiventral se reptante, radial se ereto, sem esclerênquima. Escamas do caule clatradas, freqüentemente com brilho metálico e com margens de aparência denteada; às vezes, com pêlos articulados inconspícuos. Frondes monomorfas, vernação circinada, dísticas ou, em caules radiais, polísticas, adensadas a espaçadas, bases não articuladas, com um ou dois vasos condutores, quando maduras sem apêndices epidérmicos evidentes macroscopicamente. Estípite ausente ou presente, freqüentemente curto, às vezes longo, adaxialmente sulcado distintamente até quase próximo à base. Lâmina simples, raramente furcada ou fendida, ou pinada, oblonga ou lanceolada a linear, ou cuneada, membranácea a coriácea, margens planas a revolutas. Costa presente ou raramente ausente, percurrente ou evanescente na metade basal da lâmina. Nervuras livres simples ou furcadas, ou ramificadas de forma pinada e unidas por uma comissura submarginal, ou amplamente anastomosantes, as aréolas abertas ou fechadas na margem, sem vênulas livres e incluídas nas aréolas. Esporângios agrupados em linhas de soros simples ou ramificadas, ou em soros arredondados, ou ainda difusamente espalhados sobre a superfície; indúsio verdadeiro ausente, soros freqüentemente imersos em sulcos do tecido da fronde, ou protegidos por aletas da superfície inferior da fronde ou pela margem revoluta; paráfises geralmente presentes, unisseriadas, raramente ramificadas, freqüentemente com uma célula apical modificada e expandida. Esporângio com pedicelo uni ou bisseriado na base, trisseriado apenas no extremo ápice, estômio com 4 células e ânulo com muitas células; isosporados, esporos geralmente hialinos, aclorofilados, sem perisporo proeminente, tetraédrico-globosos e triletes ou reniformes e monoletes. Fase gametofítica epígea, clorofilada, talo alongado e irregularmente ramificado, por vezes com gemas.

A família é caracterizada pela ausência de esclerênquima, presença de células espiculares alongadas (idioblastos), estrutura do estípite muito simples, escamas clatradas e esporos hialinos. A organização do tecido vascular no caule é ectoflóica (Kramer 1990).

A família, na delimitação de Crane (1997), apresenta dez gêneros, sendo dois pantropicais, três paleotropicais e cinco neotropicais e cerca de 100 espécies. Dos sete gêneros ocorrentes na América, cinco ocorrem no Sudeste do Brasil: Anetium Splitg., Hecistopteris J. Sm., Polytaenium Desv., Radiovittaria (Benedict) E.H. Crane e Vittaria Sm.

Chave para os gêneros de Vittariaceae do Sudeste do Brasil

1. Lâmina furcada; nervuras livres Hecistopteris

1. Lâmina inteira; nervuras anastomosantes

2. Nervação com uma única série de aréolas entre a costa e a margem da lâmina; paráfises presentes

3. Célula apical das paráfises filiforme a clavada; lâmina $\leq 0,4 \mathrm{~cm}$ larg. Vittaria

3. Célula apical das paráfises em forma de funil; lâmina geralmente $>0,4 \mathrm{~cm}$ larg. Radiovittaria

2. Nervação com duas ou mais séries de aréolas entre a costa e a margem da lâmina; paráfises ausentes

4. Esporângios apenas sobre as nervuras; frondes adensadas Polytaenium

4. Esporângios sobre as nervuras e sobre o tecido laminar das aréolas; frondes espaçadas Anetium 
Hecistopteris J. Sm., Lond. J. Bot. 1:193. 1842.

Tipo: Hecistopteris pumila (Spreng.) J. Sm. (三 Gymnogramma pumila Spreng.).

Plantas epífitas, raramente rupícolas. Caule protostélico, curto-reptante, dorsiventral. Frondes dísticas, adensadas, sésseis a curtamente estipitadas. Lâmina 0,8-6 cm compr., 0,5-1 cm larg., pinatífida, multifurcada ou com ápice furcado a irregularmente fendido, cuneada a flabelada, membranácea a papirácea, margens planas, costa ausente. Nervuras livres dicotomicamente ramificadas. Esporângios em soros lineares, sobre a parte distal das nervuras, mas não chegando ao ápice das mesmas, superficiais. Paráfises numerosas, com a célula apical filiforme ou em forma de funil, às vezes ramificada. Esporos triletes, tetraédrico-globosos.

A nervação livre, os soros superficiais e os esporos triletes apresentados por Hecistopteris indicam que este é um dos gêneros menos especializados da família (Tryon \& Tryon 1982). Segundo Crane et al. (1995), a célula apical das paráfises de Hecistopteris apresenta a forma de funil. Contudo, a maior parte do material analisado no presente estudo apresenta também a célula apical filiforme, concordando com Copeland (1947), Stolze (1981) e Smith (1995), entre outros.

Hecistopteris está restrito à América tropical (Tryon \& Stolze 1989), desde o México até a Bolívia e Sudeste do Brasil .

Até recentemente o gênero era tido como monotípico. Contudo, espécies novas foram reconhecidas: Hecistopteris pinnatifida R.C. Moran \& B. Øllg., no Equador e H. kaieteurensis Kelloff \& G.S. McKee, na Guiana e na região de Manaus, Brasil (Kelloff \& McKee 1998).

Na região Sudeste, o gênero está representado por espécie de ampla distribuição:

1. Hecistopteris pumila (Spreng.) J. Sm., London J. Bot. 1:193. 1842. E Gymnogramma pumila Spreng., Tent. suppl. Syst. veg.:31. 1828. Tipo: SURINAME, Weigelt s.n. (holótipo não localizado; isótipos $\mathrm{B}, \mathrm{P}$ ). Figuras 1-4.

Plantas epífitas, raramente rupícolas. Escamas do caule 1-2 $\times 0,3-0,5 \mathrm{~mm}$, lineares, castanhas, 3-8 células de largura na base. Frondes sésseis a curtamente estipitadas. Lâmina 1-4 cm compr., 0,5-1 cm larg., com ápice furcado a irregularmente fendido, cuneada a flabelada, membranácea a papirácea. Esporângios em soros lineares nos últimos ou penúltimos segmentos.
Material selecionado: BRASIL: Minas GERAIS: Sem município definido: Província de Minas Gerais, s.d., Araújo s.n. (RB 36576). Rio de Janeiro: Parati, APA Cairuçu, trilha de Ponta Negra para Cairuçu das Pedras, 11-V-1991, L. Sylvestre et al. 529 (RB); Santa Maria Madalena, Três Barras, 15-XII-1930, J.S. Lima Jr. 35 (R). São Paulo: Cananéia, Fazenda Folha Larga, km 21,5 da estrada Jacupiranga-Cananéia, 29-VIII-1997, O. Yano \& M. Lindenberg 24909 (SP); Iguape, Serra Paranapiacaba, X-1925, A.C. Brade 8423 (HB, R, RB); Miracatu, 7-VII-1978, O. Yano 1078 (SP); Ubatuba, Picinguaba, Estrada da Casa da Farinha, 5-VI-1988, J.E.L.S. Ribeiro et al. 362 (SJRP).

As frondes pequenas, geralmente furcadas e flabeladas, são às vezes quase inteiras. Segundo Tryon \& Tryon (1982) as raízes, que ocasionalmente têm sido mal interpretadas como caules, são freqüentemente longas e podem ter gemas que produzem novas plantas.

Hecistopteris pumila se assemelha a $H$. kaieteurensis em tamanho e hábito, mas pode ser distingüida desta por sua lâmina achatada e apicalmente fendida, sendo que a espécie guianense apresenta a lâmina recurvada e multifurcada. $H$. pinnatifida apresenta a fronde pinatífida.

Cresce principalmente em florestas pluviais e florestas montanas (Tryon \& Tryon 1982). Na região de estudo, esta espécie foi encontrada abaixo de $1.000 \mathrm{~m}$ de altitude, sendo comumente epífita, crescendo associada a musgos.

Hecistopteris pumila apresenta ampla distribuição na América tropical, baseada relativamente em poucos registros (Tryon \& Stolze 1989). As plantas diminutas podem ser raras ou freqüentemente não são notadas. $\mathrm{Na}$ Região Sudeste, esta espécie foi pouco coletada.

Ocorre no Sul do México, América Central, Caribe, Colômbia, Venezuela, Guianas, Equador, Peru, Bolívia e, no Brasil, nos Estados do Amazonas, Acre, Pará, Pernambuco, Bahia, Mato Grosso, Minas Gerais, Rio de Janeiro, São Paulo, Paraná e Santa Catarina.

Vittaria Sm., Mém. Acad. Roy. Sci. (Turin) 5:413. 1793. Tipo: Vittaria lineata (L.) Sm. (三Pteris lineata L.).

Plantas epífitas, geralmente pendentes, às vezes rupícolas, muito raramente terrestres. Caule solenostélico, curto-reptante, dorsiventral. Frondes dísticas, adensadas ou um pouco espaçadas, sésseis a curtamente estipitadas. Lâmina $8-120 \mathrm{~cm}$ compr., 0,1-0,4 cm larg., inteira, linear, papirácea a subcoriácea, margens planas a revolutas, costa distinta. Nervuras anastomosantes, formando uma única série de aréolas 
entre a costa e a margem da lâmina, as nervuras laterais anastomosando para formar uma nervura comissural submarginal, paralela à costa. Esporângios em soros lineares, um de cada lado da costa, ao longo da comissura submarginal, em sulcos rasos ou profundos. Paráfises numerosas, delgadas a robustas, com a célula apical alargada ou não, filiforme a clavada. Esporos monoletes e reniformes ou triletes e tetraédrico-globosos.

As espécies neotropicais de Vittaria são facilmente distingüidas daquelas de Radiovittaria pelas lâminas mais estreitas e pela forma da célula apical da paráfise. Além disso, o estípite de Vittaria é freqüentemente mal diferenciado da lâmina estreita, enquanto o de Radiovittaria é distinto e geralmente escurecido.

Segundo Tryon \& Tryon (1982), Vittaria (sensu lato) é primariamente um gênero de florestas pluviais, florestas sombreadas e nebulares, menos freqüentemente de hábitats parcialmente sombreados ou mais abertos. É geralmente epífita, e ocorre menos freqüentemente sobre madeira podre e/ou sobre penedos ou rochedos, e raramente sobre bancos de terra. Nas Américas, o gênero cresce em florestas pluviais de planície, florestas montanas e sombreadas, geralmente encontrado abaixo de $1.000 \mathrm{~m}$ de altitude, com algumas espécies, como V. graminifolia, crescendo até $3.300 \mathrm{~m}$ de altitude.

A maioria das espécies é neotropical, com uma única espécie na África e ilhas do Sudeste do Oceano Índico (Crane 1997). Segundo Tryon \& Tryon (1982), Vittaria sensu lato (que corresponde aos gêneros Haplopteris, Radiovittaria e Vittaria, no sistema adotado neste trabalho) ocorre nas regiões tropicais e subtropicais do globo, com cerca de 60-70 espécies.

No Sudeste do Brasil, o gênero está representado por duas espécies, que podem ser reconhecidas através dos caracteres apresentados na chave a seguir:

1. Paráfises delgadas, com a célula apical não ou apenas levemente alargada; esporos sempre monoletes, reniformes 1. V. lineata

1. Paráfises robustas, com a célula apical alargada; esporos predominantemente triletes, tetraédricoglobosos 2. V. graminifolia

1. Vittaria lineata (L.) Sm., Mém. Acad. Roy. Sci. (Turin) 5:421, t.9, fig.5. 1793. $\equiv$ Pteris lineata L., Sp. pl. 2: 1073. 1753. Tipo: REPÚBLICA DOMINICANA: Santo Domigo, Plumier, Traité foug. Amér. t.143. 1705 (lectótipo designado por Tryon, Contr. Gray Herb. 194:213. 1964).

Figuras 5-8.

Plantas epífitas. Escamas do caule 5-10 $\times$ 0,2-0,8 $\mathrm{mm}$, lineares, nigrescentes a castanhas ou ocasionalmente alaranjadas, 3-8 células de largura na base. Estípite mais claro que a lâmina ou concolor quando seco e um pouco achatado. Lâmina $8-120 \mathrm{~cm}$ compr., 0,2-0,3 cm larg., linear, papirácea a subcoriácea, margens planas a revolutas. Esporângios em soros lineares, um pouco distanciados das margens, em sulcos profundos, freqüentemente com aletas nas margens dos sulcos. Paráfises castanhas a levemente castanho-avermelhadas, delgadas, com célula apical não ou muito pouco alargada. Esporos monoletes, reniformes.

Material selecionado: BRASIL: EspírITo SANTO: Castelo, Braço do Sul, 16-VIII-1948, A.C. Brade 19423 (RB); Conceição da Barra, Reserva da Fazenda São Joaquim, 3-XI-1987, H.Q.B. Fernandes 2236 (MBML); Linhares, Reserva Florestal de Linhares, 24-XI-1998,
D.A. Folli 3291 (BHCB, CVRD); Santa Teresa, Estação Ecológica de Santa Lucia, 24-II-1996, A. Salino 2617 (BHCB). Minas Gerais: Camanducaia, Vila Monte Verde, 24-IX-1979, P.G. Windisch 2501 (HB); Cambuí, divisa com Camanducaia e Gonçalves, descida da Pedra de São Domingos, 17-IV-1999, F.R. Nonato \& P.G. Windisch 595 (R); Carangola, Fazenda Santa Rita, 26-V-1989, A. Salino 742 (BHCB, SJRP); Cristina, VIII-1912, H. Luederwaldt s.n. (SPF 106952); Ouro Preto, Serra de Ouro Preto, s.d., L. Damazio s.n. (OUPR 549); Poços de Caldas, Morro do Ferro, 10-X-1966, M. Emmerich 2864 (HB); Sapucaí-Mirim, Serra da Mantiqueira, III-1992, A. Salino 1300 (UEC). Rio DE JANEIRO: Itatiaia, Estrada para Agulhas Negras, Brejo da Lapa, 26-IV-1989, L. Sylvestre et al. 226 (RB); Nova Friburgo, Reserva Ecológica Macaé de Cima, 23-IV-1999, F.R. Nonato et al. 606 (R); Nova Iguaçu, Tinguá, 2-VI-1961, J.P. Lanna Sobrinho 80 (GUA); Parati, APA Cairuçu, trilha de Ponte Negra para Cairuçu das Pedras, 11-V-1991, L. Sylvestre et al. 530 (RB); Rio de Janeiro, Parque Nacional da Tijuca, XI-1999, F.R. Nonato et al. 671 (R); Santa Maria Madalena, Alto do Desengano, X-1934, J.S. Lima 273 (RB); Teresópolis, Parque Nacional Serra dos Órgãos, trilha para a Pedra do Sino, 3-VI-1999, F.R. Nonato \& J.M.A. Braga 634 


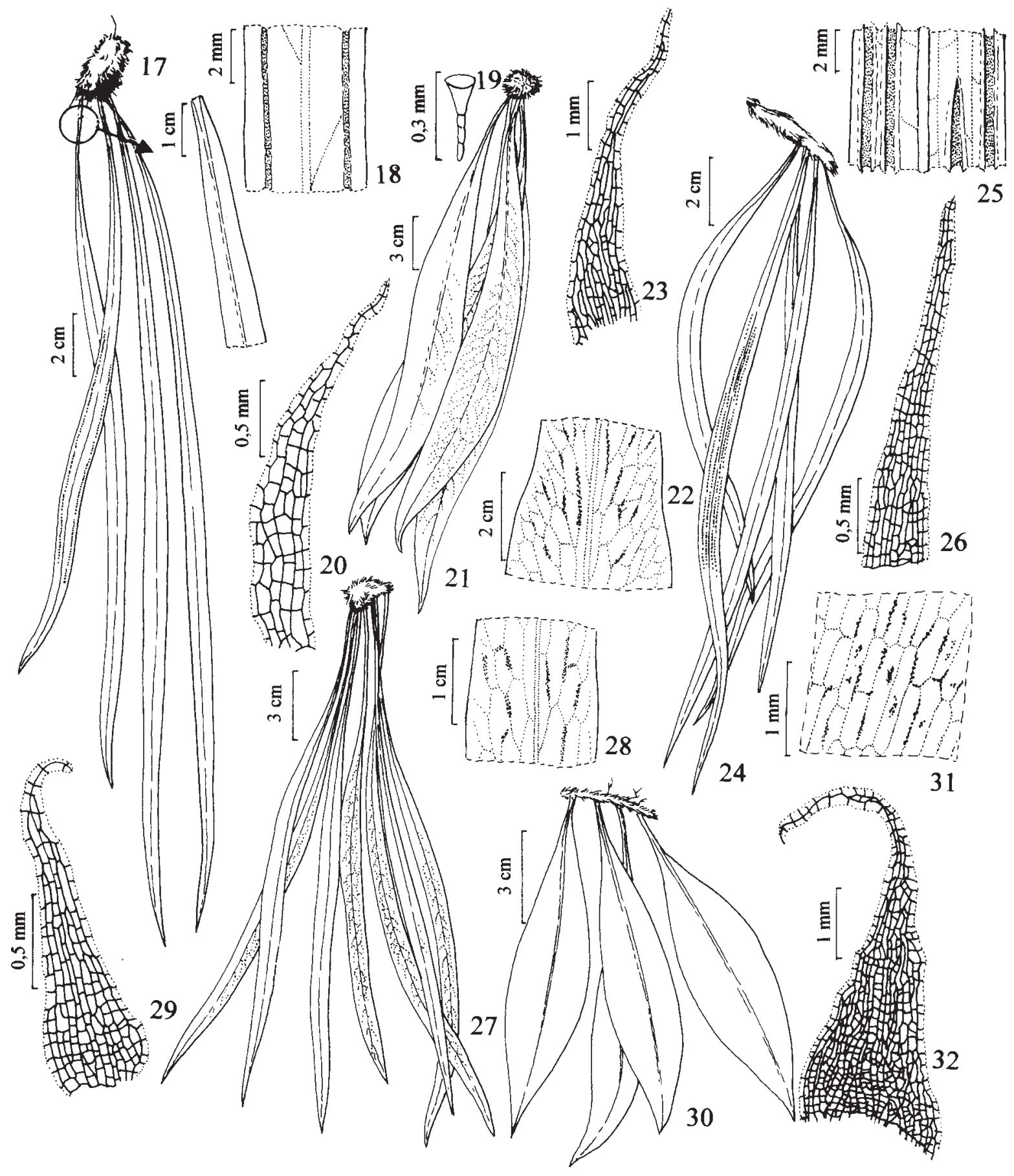

Figuras 1-4. Hecistopteris pumila. 1. hábito. 2. detalhe da nervação. 3. paráfise. 4. escama do caule. Figuras 5-8. Vittaria lineata. 5. hábito e detalhe da lâmina fértil. 6. detalhe da nervação 7. paráfise. 8. escama do caule. Figuras 9-12. Vittaria graminifolia. 9. hábito e detalhe da lâmina fértil. 10. detalhe da nervação. 11. paráfise. 12. escama do caule. Figuras 13-16. Radiovittaria stipitata. 13. hábito. 14. detalhe da lâmina fértil e da nervação. 15. paráfise. 16. escama do caule (1-4 - Brade 8423; 5-8 - Windisch 6841; 9-12 - Nonato 608; 13-16 - Nonato 539).

Figures 1-4. Hecistopteris pumila. 1. habit. 2. detail of venation. 3. paraphysis. 4. stem scale. Figures 5-8. Vittaria lineata. 5. habit and detail of the fertile lamina. 6. detail of venation. 7. paraphysis. 8. stem scale. Figures 9-12. Vittaria graminifolia. 9. habit and detail of the fertile lamine. 10. detail of venation. 11. paraphysis. 12. stem scale. Figures 13-16. Radiovittaria stipitata. 13. habit. 14. detail of fertile lamina and venation. 15. paraphysis. 16. stem scale (1-4 - Brade 8423; 5-8 - Windisch 6841; 9-12 Nonato 608; 13-16 - Nonato 539). 
(R). São Paulo: Campos de Cunha, Campos da Bocaina, Serra do Mar (acesso Campos de Cunha e Macacos), 4-III-1992, P.G. Windisch 6841 (SJRP); Campos do Jordão, subida para São José dos Alpes, 16-IV-1999, F.R. Nonato \& P.G. Windisch 544 (R); Cananéia, Ilha do Cardoso, Rio Tapera, 23-VII-1981, O. Yano 3725 (SP); Cunha, Pedra da Marcela, 13-VII-1997, F.R. Nonato et al. 388 (SJRP); Iguape, Morro das Pedras, IX-1917, A.C. Brade 7663 (HB); Iporanga, Parque Estadual Turístico do Alto Ribeira (PETAR), núcleo Ouro Grosso, 28-X-1997, F. Tomasetto 41 (SJRP); Pindamonhangaba, Distrito de São José dos Alpes, 16-IV-1999, F.R. Nonato \& P.G. Windisch 551 (R); Santo André, Alto da Serra, 14-VII-1912, A.C. Brade 5247-a (HB); São Paulo, Serra da Cantareira, 8-IX-1912, A.C. Brade 5298 (HB); Ubatuba, Estrada do Farol, 29-XII-1997, F.P. Athayde Filho 342 (SJRP).

Vittaria lineata é caracterizada por apresentar soros em sulcos profundos com aletas em ambos os lados, paráfises com a célula apical não ou apenas levemente alargada e esporos monoletes. É semelhante a $V$. graminifolia, com a qual é freqüentemente confundida, sendo separadas, principalmente, pela diferença na forma dos esporos.

No Sudeste, esta espécie é a mais facilmente encontrada, ocorrendo em ambientes sombreados e úmidos, porém mais rara em locais pouco sombreados. Ocorre desde o nível do mar até $2.000 \mathrm{~m}$ de altitude, preferencialmente até $1.000 \mathrm{~m}$. É essencialmente epífita, ocorrendo também sobre troncos em decomposição.

Ocorre no Sul dos Estados Unidos da América, México, América Central, Caribe, Colômbia, Venezuela, Guianas, Equador, Peru, Bolívia, Brasil, Paraguai e Uruguai. No Brasil, ocorre nos Estados do Amazonas, Amapá, Pará, Maranhão, Ceará, Pernambuco, Bahia, Mato Grosso, Mato Grosso do Sul, Minas Gerais, Espírito Santo, Rio de Janeiro, São Paulo, Paraná, Santa Catarina e Rio Grande do Sul.

2. Vittaria graminifolia Kaulf., Enum. filic.:192. 1824. Tipo: BRASIL, Otto s.n. (holótipo LZ, destruído; isótipo E).

Figuras 9-12.

Plantas epífitas, às vezes rupícolas. Escamas do caule 4-6 $\times$ 0,3-0,8 mm, lanceoladas, castanhoacinzentadas a alaranjadas, $4-12$ células de largura na base. Estípite mais claro que a lâmina ou concolor quando seco e um pouco achatado. Lâmina $8-50 \mathrm{~cm}$ compr., 0,1-0,2 cm larg., linear, papirácea, margens planas a revolutas. Esporângios em soros lineares, próximos às margens, em sulcos pouco profundos, com ou sem aletas nas margens dos sulcos. Paráfises castanho-avermelhadas a castanho-avermelhadas escuras, robustas, com a célula apical alargada. Esporos predominantemente triletes, tetraédrico-globosos (raro esporos triletes e monoletes na mesma planta).

Material selecionado: BRASIL: EsPíRITO SANTO: Santa Teresa, Vargem Alta, 28-VIII-1986, H.Q.B. Fernandes 1446 (GUA, MBML). Minas Gerais: Carangola, Serra do Brigadeiro, Fazenda Neblina, 28-V-1989, A. Salino 780 (BHCB, SJRP); Ouro Preto, Serra do Frazão, 1935, J. Badini s.n. (OUPR 750); sem município definido: região de Passa Quatro, Fazenda São Bento, XI-1948, J. Vidal 2142 (R). Rıo DE JANEIRo: Mangaratiba, Reserva Rio das Pedras, 26-VIII-1998, F.R. Nonato et al. 537 (R, RUSU); Nova Friburgo, Reserva Ecológica de Macaé de Cima, 23-IV-1999, F.R. Nonato et al. 608 (R); Teresópolis, Parque Nacional Serra dos Órgãos, trilha para Pedra do Sino, 3-VI-1999, F.R. Nonato \& J.M. A. Braga 651 (R); sem município definido: Itatiaia, IX-1934, A.C. Brade 14083 (RB). São Paulo: Analândia, Serra do Cuscuzeiro, Gruta Nossa Senhora de Lourdes, 25-X-1986, A. Salino 50 (BHCB, SJRP, UEC); Campinas, Barão Geraldo, Reserva Florestal Santa Genebra, 16-III-1992, A. Salino 1327 (UEC); Cunha, Pedra da Marcela, 13-VII-1997, F.R. Nonato et al. 391 (SJRP); Iguape, Morro das Pedras, V-1922, A.C. Brade 8454 (HB); São Miguel Arcanjo, divisa com Capão Bonito e Sete Barras, Parque Estadual Carlos Botelho, 8-VI-1992, J.A. Lombardi 133 (UEC); Salesópolis, Estação Biológica de Boracéia, 14-II-1999, P.H. Labiak 991 (SJRP, SP); Teodoro Sampaio, Região do Pontal do Paranapanema, Parque Estadual Morro do Diabo, 16-I-1995, M.R. Pietrobom-Silva 1553 (SJRP); Ubatuba, estrada para Taubaté, área do Parque Estadual da Serra do Mar, 3-II-1996, A. Salino 2524 (BHCB).

Vittaria graminifolia apresenta muitas semelhanças morfológicas com $V$. lineata, conforme discutido sob $V$. lineata. Nos espécimes que apresentam esporos monoletes e triletes, estes últimos são produzidos em maior quantidade, conforme já registrado por Lorscheitter et al. (1998). Esses espécimes se assemelham no restante de suas características a $V$. graminifolia, sendo por isso identificados como tal.

Tryon (1964b) indicou que o isótipo de Vittaria graminifolia está depositado em E e é uma coleta pertencente ao Herbário de Greville. Desta forma, a lectotipificação anterior desta espécie, proposta pelo próprio (Tryon 1964a), foi invalidada. 
Os principais caracteres utilizados para reconhecer Vittaria scabrida Klotzsch ex Fée (Baker 1870) são a presença de uma depressão na célula apical das paráfises (com aspecto de capuz, em determinado ângulo de observação) e nas dimensões das frondes. Contudo, o exame de espécimes determinados como $V$. scabrida e como $V$. graminifolia revelou a existência de paráfises com célula apical expandida ou ainda sem expansão, entre as chamadas paráfises cuculiformes. Como destacado por Schaffer-Fehre (1996) seria importante o estudo de paráfises usando material fresco fixado, para análise adequada. Concluímos que a estrutura "cuculiforme" muito provavelmente é resultado das condições ambientais ou daquelas durante a secagem das amostras. $\mathrm{O}$ tamanho das frondes também não se revelou caráter confiável para distinção. Assim sendo, $V$. scabrida seria provável sinônimo de $V$. graminifolia, sendo necessário uma análise mais detalhada.

Vittaria graminifolia ocorre preferencialmente em florestas pluviais tropicais, e também em locais úmidos e sombreados, como matas ciliares, em altitudes que variam desde o nível do mar até $2.000 \mathrm{~m}$, embora possa ocorrer até $3.300 \mathrm{~m}$ (Tryon \& Tryon 1982). Stolze (1981) também relata que $V$. graminifolia ocorre em altitudes mais elevadas, geralmente entre 1.000-3.000 m, embora tenha encontrado espécimes em altitudes inferiores. Esta espécie é geralmente epífita, podendo ocorrer menos freqüentemente sobre troncos em decomposição ou sobre rochas.

Ocorre nos Estados Unidos da América, México, América Central, Caribe, Colômbia, Venezuela, Guianas, Equador, Peru, Bolívia, Brasil e Uruguai. No Brasil, ocorre nos Estados do Amazonas, Pernambuco, Bahia, Mato Grosso, Minas Gerais, Espírito Santo, Rio de
Janeiro, São Paulo, Paraná, Santa Catarina e Rio Grande do Sul.

Radiovittaria (Benedict) E. H. Crane, Syst. Bot. 22(3):514. 1997. (三Vittaria subg. Radiovittaria Benedict).

Tipo: Radiovittaria remota (Fée) E.H. Crane (三Vittaria remota Fée).

Plantas epífitas, geralmente pendentes, raramente rupícolas. Caule solenostélico, subereto, radial. Frondes polísticas, adensadas, estipitadas; estípite mais escuro que a lâmina. Lâmina 5-110 cm compr., 0,4-1,8 cm larg., inteira, linear a lanceolada, papirácea a subcoriácea, margens planas, costa distinta. Nervuras anastomosantes, formando uma única série de aréolas entre a costa e a margem da fronde, as nervuras laterais anastomosando para formar uma nervura comissural submarginal paralela à costa. Esporângios em soros lineares, um de cada lado da costa, submarginais, contínuos a descontínuos, superficiais ou em sulcos rasos ou profundos. Paráfises numerosas, com a célula apical em forma de funil, às vezes ramificadas. Esporos monoletes, reniformes.

Radiovittaria abrange as espécies neotropicais de Vittaria sensu lato que apresentam lâmina com mais de $4 \mathrm{~mm}$ de largura, esporos reniformes e monoletes e caule de simetria radial.

O gênero é encontrado na América Central, América do Sul e Antilhas (Crane 1997), apresentando cerca de sete espécies nas Américas (Benedict 1914), das quais duas estão representadas no Sudeste do Brasil, podendo ser reconhecidas através dos caracteres apresentados na chave a seguir:

1. Escamas do caule lineares, 1-2 células de largura na base; estípite cilíndrico ou achatado apenas na própria base, não alado 1. R. stipitata

1. Escamas do caule lanceoladas, 3-8 células de largura na base; estípite inteiramente achatado, totalmente ou a maior parte estreitamente alado 2. R. gardneriana

1. Radiovittaria stipitata (Kunze) E.H. Crane, Syst. Bot. 22(3):514. 1997. 三Vittaria stipitata Kunze, Linnaea 9:77. 1834. Tipo: PERU, HuÁnUCO, Pampayacu, Poeppig Diar. 1121 (holótipo LZ, destruído; isótipo P). Figuras 13-16.

Plantas epífitas. Escamas do caule 1-2,5 $\times$ 0,1-0,3 mm, lineares, castanho-escuras a atropurpúreas, 1-3 células de largura na base. Estípite cilíndrico ou achatado apenas na própria base, não alado. Lâmina
10-75 cm compr., 0,4-0,6 cm larg., linear, membranácea a papirácea, margens planas. Esporângios em soros lineares, contínuos, em sulcos profundos. Paráfises avermelhadas com a célula apical em forma de funil.

Material selecionado: BRASIL: MinAs GeraIs: Mariana, Mata da CVRD, 19-IX-1989, L. Krieger et al. 24085 (OUPR); Ouro Preto, Itacolomy, 1941, J. Badini s.n. (OUPR 3604). Rio DE JANEIRO: Mangaratiba, Reserva Rio das Pedras, 26-VIII-1998, F.R. Nonato 
et al. 539 (R, RUSU). São PaUlo: Cananéia, XII-1962, L. Travassos s.n. (RB 169917); Iguape, Morro das Pedras, X-1915, A.C. Brade 7662 (HB); Juquiá, Fazenda Poço Grande, 1925, A.C. Brade 21328 (HB); Miracatu, 7-VII-1978, O. Yano 1079 (SP); Sete Barras, Fazenda Intervales, Base de Saibadela, 20-VII-1994, A. Salino 2006 (BHCB); Ubatuba, Picinguaba, Estrada da Casa da Farinha, 12-III-1989, A. Furlan et al. 777 (SJRP).

Radiovittaria stipitata apresenta os soros alongados em sulcos profundos, perceptíveis mesmo quando os soros estão imaturos. Os soros são mais estreitos e com paráfises menos numerosas que em $R$. gardneriana. Pode ser confundida com $R$. moritziana Mett. (que não ocorre no Brasil) devido ao estípite cilíndrico ou achatado apenas na base, não alado. Segundo Tryon \& Stolze (1989), R. stipitata pode ser reconhecida pelas escamas do caule com duas células de largura na base (vs. seis ou mais células de largura em $R$. moritziana).

Ocorre preferencialmente em florestas pluviais tropicais, sombreadas e úmidas, até $1.700 \mathrm{~m}$ de altitude, freqüentemente sobre caule de Cyatheaceae. As populações de Radiovittaria stipitata são pouco numerosas em comparação com as espécies do gênero Vittaria, que possuem muitos indivíduos, formando tufos de frondes.

Ocorre no sul do México, América Central, Caribe (Grandes Antilhas exceto Porto Rico), Colômbia, Venezuela, Guianas, Equador, Peru, Bolívia e, no Brasil, nos Estados da Bahia, Minas Gerais, Rio de Janeiro, São Paulo, Paraná e Santa Catarina.

2. Radiovittaria gardneriana (Fée) E.H. Crane, Syst. Bot. 22(3):514. 1997. 三Vittaria gardneriana Fée, Mém. foug. 3:15, t.3, fig.1, 1852. Tipo: BRASIL, Rio DE JaneIro, Serra dos Órgãos, Gardner 147 (lectótipo designado por Benedict, Bull. Torrey Bot. Club 41:401. 1914, BM).

Figuras 17-20.

Plantas epífitas, raramente rupícolas. Escamas do caule 2-4 × 0,3-0,5 mm, lanceoladas, castanhas a atropurpúreas, 3-8 células de largura na base. Estípite inteiramente achatado, totalmente ou a maior parte estreitamente alado. Lâmina 5-30 cm compr., 0,4-0,7 cm larg., linear-elíptica ou um pouco mais larga na porção mediana, papirácea, margens planas. Esporângios em soros lineares, contínuos a descontínuos, em sulcos rasos. Paráfises avermelhadas com a célula apical em forma de funil.
Material selecionado: BRASIL: EspíRITo SANTO: Castelo, Forno Grande, 12-VIII-1948, A.C. Brade 19240 (RB). Minas Gerais: Ouro Preto, Serra do Frazão, 1948, J. Badini s.n. (OUPR 20322). RIO DE JANeIro: Itatiaia, trilha para o Véu da Noiva, 28-VIII-1989, L. Sylvestre et al. 274 (RB, SJRP); Santa Maria Madalena, VI-1933, J. S. Lima 168 (RB); Teresópolis, Córrego Beija-flor, 19-IX-1929, A.C. Brade 9282 (R). São PAULO: Capão Bonito, Fazenda Intervales, Trilha da Cassadinha, 29-X-1991, A. Salino 1137 (BHCB, SJRP, UEC); Santo André, Alto da Serra, 14-VII-1912, A.C. Brade 5250 (HB); Ubatuba, Parque Estadual da Serra do Mar, Núcleo Picinguaba, estrada para Casa da Farinha, 30-I-1996, A. Salino 2451 (BHCB).

Radiovittaria gardneriana apresenta as frondes geralmente menores que as de $R$. stipitata; suas frondes são mais largas na parte central (elíptica) quando maduras; quando a fronde é jovem esta diferença não é tão perceptível. Pode ser confundida com Ananthacorus angustifolius Underw. \& Maxon (vitariácea que também ocorre no Brasil), que possui duas séries de aréolas em cada lado da costa, diferenciando-se desta por apresentar apenas uma série de aréolas.

Ocorre preferencialmente em florestas pluviais tropicais, sombreadas e úmidas, principalmente em altitudes que variam entre 800 e $2.000 \mathrm{~m}$. É geralmente epífita, podendo ocorrer menos freqüentemente sobre rochas.

Ocorre na Costa Rica, Panamá, Caribe, Colômbia, Venezuela, Guianas, Peru, Bolívia e, no Brasil, apenas nos Estados de Minas Gerais, Espírito Santo, Rio de Janeiro e São Paulo.

Polytaenium Desv., Mém. Soc. Linn. Paris 6:218. 1827. Tipo: Polytaenium lanceolatum (Sw.) Desv. (三Vittaria lanceolata $\mathrm{Sw}$.

Plantas epífitas, por vezes rupícolas. Caule solenostélico, curto-reptante, dorsiventral. Frondes dísticas, adensadas ou um pouco espaçadas, sésseis a curtamente estipitadas. Lâmina 10-50 cm compr., 0,4-4 cm larg., inteira, linear, lanceolada a oblanceolada, papirácea a coriácea, margens planas ou um pouco revolutas ou ainda onduladas, costa distinta. Nervuras anastomosantes, as nervuras laterais formando duas ou mais séries de aréolas entre a costa e a margem da fronde. Esporângios sobre as nervuras, em soros lineares, longos e contínuos formando vários sulcos profundos paralelos à costa, ou curtos e interrompidos, superficiais ou em sulcos, oblíquos à costa. Paráfises ausentes. 
Esporos triletes, tetraédrico-globosos.

Polytaenium caracteriza-se pela costa distinta que se estende até o ápice da fronde e ausência de paráfises. Os gêneros Antrophyum e Polytaenium são relacionados e têm sido unidos ou segregados, de diferentes maneiras (Benedict 1911, Copeland 1947, Kramer 1990, Crane 1997). Antrophyum é, segundo Tryon (1964a), um gênero do Velho Mundo que possui paráfises, com uma única espécie no México e América Central; já Polytaenium é um gênero americano e sem paráfises. Posteriormente, Tryon \& Tryon (1982) consideraram Antrophyum de um modo mais amplo incluindo Polytaenium. Seus representantes crescem em florestas úmidas, freqüentemente à sombra, geralmente como epífitas e, algumas vezes, sobre rochedos úmidos.

Polytaenium ocorre exclusivamente na América Central, América do Sul e Antilhas (Crane 1997), com cerca de 17-18 espécies (Tryon \& Tryon 1982).

Está representado no Sudeste do Brasil por três espécies, que podem ser reconhecidas pela chave a seguir:

1. Lâmina oblanceolada, estreitando-se gradualmente apenas em direção à base; aréolas oblíquas à costa 1. P. cajenense

1. Lâmina linear a linear-elíptica, estreitando-se gradualmente em ambas extremidades; aréolas paralelas ou subparalelas à costa

2. Esporângios em soros lineares longos, a maioria em linhas contínuas, sobre as aréolas paralelas à costa, profundamente imersos no tecido laminar 2. P. lineatum

2. Esporângios em soros lineares curtos, em linhas descontínuas, sobre as aréolas subparalelas à costa, superficiais ou levemente imersos no tecido laminar. 3. P. feei

1. Polytaenium cajenense (Desv.) Benedict, Bull. Torrey Bot. Club 38:169. 1911. 三 Antrophyum cajenense (Desv.) Spreng., Syst. veg. 4:67. 1827. $\equiv$ Hemionitis cajenensis Desv., Ges. Naturf. Freunde Berlin Mag. Neuesten Entdeck. Gesammten Naturk. 5:311. 1811. Tipo: GUIANA FRANCESA, Anon., Herb. Desv. (holótipo P; isótipo B).

Figuras 21-23.

Plantas epífitas, por vezes rupícolas. Escamas do caule 3-6 × 0,3-1 mm, linear-lanceoladas, castanhas, 4-12 células de largura na base. Estípite concolor, mais claro ou mais escuro do que a lâmina, castanho a verde abaxialmente, quando seco castanho-claro a escuro, fortemente alado. Lâmina 10-35 cm compr., 1-4 cm larg., oblanceolada, estreitada gradualmente apenas em direção à base, coriácea, margens planas. Nervuras laterais formando 3-6 séries de aréolas entre a costa e a margem da fronde, oblíquas à costa. Esporângios em soros lineares curtos, sobre as nervuras, descontínuos, numerosos, superficiais ou levemente imersos no tecido laminar.

Material selecionado: BRASIL: EsPírITo SANTO: Vargem Alta, 3-VI-1949, A.C. Brade 19986 (RB). Minas Gerais: Caratinga, Estação Biológica de Caratinga, Fazenda Montes Claros, 5-IX-1998, A. Salino et al. 4307 (BHCB); Coronel Pacheco, Fazenda da Companhia, 3-V-1944, E.P. Heringer 1405 (RB). Rio de Janeiro: Duque de Caxias, Distrito de Xerém, 17-X-1999, J.M.A. Braga 5484 (RB, SJRP); Nova Iguaçu, Reserva Biológica de Tinguá, Cachoeira de Serra Velha, 18-IV-1995, L. Sylvestre et al. 1168 (RBR); sem município definido: Itatiaia, VI-1913, A.C. Brade s.n. (RB 36558). São PAUlo: Iguape, Serra da Paranapiacaba, X-1925, A.C. Brade 21326 (HB); São Paulo, Serra do Mar, IX-1906, G. Edwall s.n. (RB 36557).

Polytaenium cajenense pode ser reconhecida pelas lâminas oblanceoladas, geralmente verde-pardas quando secas, aréolas oblíquas com relação à costa e soros ligeiramente fundidos. É muito similar a P. brasilianum Desv. com relação à forma da lâmina, nervuras e soriação, diferindo apenas na textura da lâmina ( $P$. brasilianum tem a lâmina papirácea) e no tecido da lâmina decorrente, sendo concolor ou mais escuro que a costa, em $P$. cajenense, e mais claro que a costa, em $P$. brasilianum. Como estas duas espécies não diferem significativamente em outras características, $P$. brasilianum é considerada, por alguns autores, como variação de $P$. cajenense (Tryon \& Stolze 1989).

Pode ser confundida com Polytaenium guayanense (Hieron.) Alston, espécie que também ocorre no norte do Brasil e é facilmente distinguível pelas frondes estreitas e elípticas, que se afilam subigualmente até o ápice e a base.

Polytaenium cajenense é geralmente epífita, podendo ocorrer sobre rochas, preferencialmente em 
florestas pluviais, tanto tropicais como equatoriais, do nível do mar até $1.700 \mathrm{~m}$ de altitude.

Ocorre no México, América Central, Caribe, Colômbia, Venezuela, Guianas, Equador, Peru, Bolívia e, no Brasil, nos Estados do Amazonas, Acre, Pará, Pernambuco, Bahia, Mato Grosso, Minas Gerais, Espírito Santo, Rio de Janeiro, São Paulo, Paraná e Santa Catarina.

2. Polytaenium lineatum (Sw.) J. Sm., J. Bot. (Hooker) 4:68. 1841. = Hemionitis lineata Sw. Prodr.:129. 1788. $\equiv$ Antrophyum lineatum (Sw.) Kaulf., Enum. filic.:199. 1824. Tipo: JAMAICA, Swartz s.n. (holótipo S; isótipo B). =Vittaria lanceolata Sw., Ges. Naturf. Freunde Berlin Neue Schriften 2:133, t.7, fig.5. 1799. $\equiv$ Polytaenium lanceolatum (Sw.) Desv., Mém. Soc. Linn. Paris 6:218. 1827. Tipo: baseado em Hemionitis lineata Sw.

Figuras 24-26.

Plantas epífitas, por vezes rupícolas. Escamas do caule 3-7 $\times$ 0,5-1 mm, lanceoladas, castanhas, 4-8 células de largura na base. Estípite quase concolor com a lâmina, castanho a verde-claro abaxialmente, quando seco mais escuro, fortemente alado. Lâmina $10-40 \mathrm{~cm}$ compr., 0,4-4 cm larg., linear a linear-elíptica, estreitada gradualmente em ambas extremidades, coriácea, margens planas ou um pouco revolutas ou ainda onduladas. Nervuras laterais formando 2-4 séries de aréolas entre a costa e a margem da fronde, paralelas à costa. Esporângios em soros lineares longos, sobre as nervuras, contínuos, formando 1-4 linhas entre a costa e as margens da fronde, profundamente imersos no tecido laminar, formando sulcos freqüentemente com aletas nas margens.

Material selecionado: BRASIL: Espírito SANTo: Cachoeiro de Itapemirim, Fazenda Santo Antônio da Pedra Branca, 26-V-1949, A.C. Brade 19901 (RB); Itarana, Jatiboca, 25-V-1946, A.C. Brade et al. s.n. (RB 182653). Minas Gerais: Araponga, Parque Estadual da Serra do Brigadeiro, nas proximidades da sede, 10-VII-1999, A. Salino 4878 (BHCB, SJRP); Lagoa Santa, s.d., L. Damazio s.n. (RB 36559); Sapucaí-Mirim, Serra da Mantiqueira, III-1992, A. Salino 1299 (UEC). Rio DE JANEIRO: Nova Friburgo, Reserva Ecológica Macaé de Cima, 23-IV-1999, F.R. Nonato et al. 605 (R); Nova Iguaçu, Tinguá, Estrada Mineira, 3-VI-1961, H.E. Strang 302 (GUA); Petrópolis, Serra dos Órgãos, Fazenda Bonfim, 3-VII-1982, J. Barcia 1569 (R); Santa Maria Madalena, Pedra Dubois, IX-1934, A.C. Brade \& J.S. Lima 13180 (RB); Teresópolis, Parque Nacional Serra dos Órgãos, trilha para Pedra do Sino, 3-VI-1999, F.R.
Nonato \& J.M.A. Braga 646 (R). São Paulo: Analândia, Serra do Cuscuzeiro, Sítio Bela Vista, VIII-1993, A. Salino s.n. (BHCB 29987); Atibaia, Pedra Grande, Fazenda Grota Funda, 23-V-1987, L.C. Bernacci et al. 19663 (SJRP, UEC); Campos do Jordão, IV-1937, L. Lanstyack s.n. (RB 33219); Iguape, Morro das Pedras, VI-1916, A.C. Brade 8483 (HB); São Paulo, Serra da Cantareira, VI-1913, F. Tamandaré 851 (RB); sem município definido: Serra da Bocaina, Sertão da Bocaina, próximo à Casa do Peixe, 8-II-1959, G.F.J. Pabst 4716 (HB).

Polytaenium lineatum é caracterizada por apresentar vários soros longos e submersos, paralelos à costa, freqüentemente com aletas nas margens dos sulcos. A lâmina de $P$. lineatum é estreita e afila gradualmente em direção ao ápice e a base. Na parte mais larga (porção central) pode apresentar de $1 \mathrm{a} 2 \mathrm{~cm}$ de largura e então a lâmina é maior do que $25 \mathrm{~cm}$ de comprimento. Em P. cajenense, a lâmina apresenta 3 a $4 \mathrm{~cm}$ de largura na porção mais larga, com a lâmina menor do que $25 \mathrm{~cm}$ de comprimento.

Espécie preferencialmente epífita, pode também ser encontrada sobre rochas, em florestas pluviais tropicais, e também em locais sombreados e úmidos, como matas ciliares, geralmente em altitudes de 800 a $2.000 \mathrm{~m}$.

Ocorre no México, América Central, Caribe, Colômbia, Venezuela, Guianas, Equador, Peru, Bolívia e, no Brasil, nos Estados da Bahia, Minas Gerais, Espírito Santo, Rio de Janeiro, São Paulo, Paraná, Santa Catarina e Rio Grande do Sul.

3. Polytaenium feei (W. Schaffn. ex Fée) Maxon, Sci. Surv. Porto Rico \& Virgin Islands 6:405. 1926. $\equiv$ Antrophyum feei W. Schaffn. ex Fée, Mém. foug. 7:42. t.22, fig.1. 1857. Tipo: MÉXICO, Vera Cruz, Schaffner 133 (holótipo provavelmente em P; isótipo $\mathrm{K}$ ).

=Hemionitis lanceolata L., Sp. pl. 2:1077. 1753. $\equiv$ Antrophyum lanceolatum (L.) Kaulf., Enum. filic.:198.1824. $\equiv$ Polytaenium lanceolatum (L.) Benedict, Bull. Torrey Bot. Club 38:169. 1911. nom. illeg., non Desv. (1827). Tipo: SÃO VICENTE: São Vicente Plumier, Traité foug. Amér. t.127, fig.C. 1705 (lectótipo designado por Proctor, Ferns of Jamaica:258. 1985).

Figuras 27-29.

Plantas epífitas, por vezes rupícolas. Escamas do caule 1,5-3 × 0,4-0,6 mm, lanceoladas, castanhas, iridescentes, $4-8$ células de largura na base. Frondes sésseis. Lâmina 15-40 cm compr., 0,8-2 cm larg., linear 


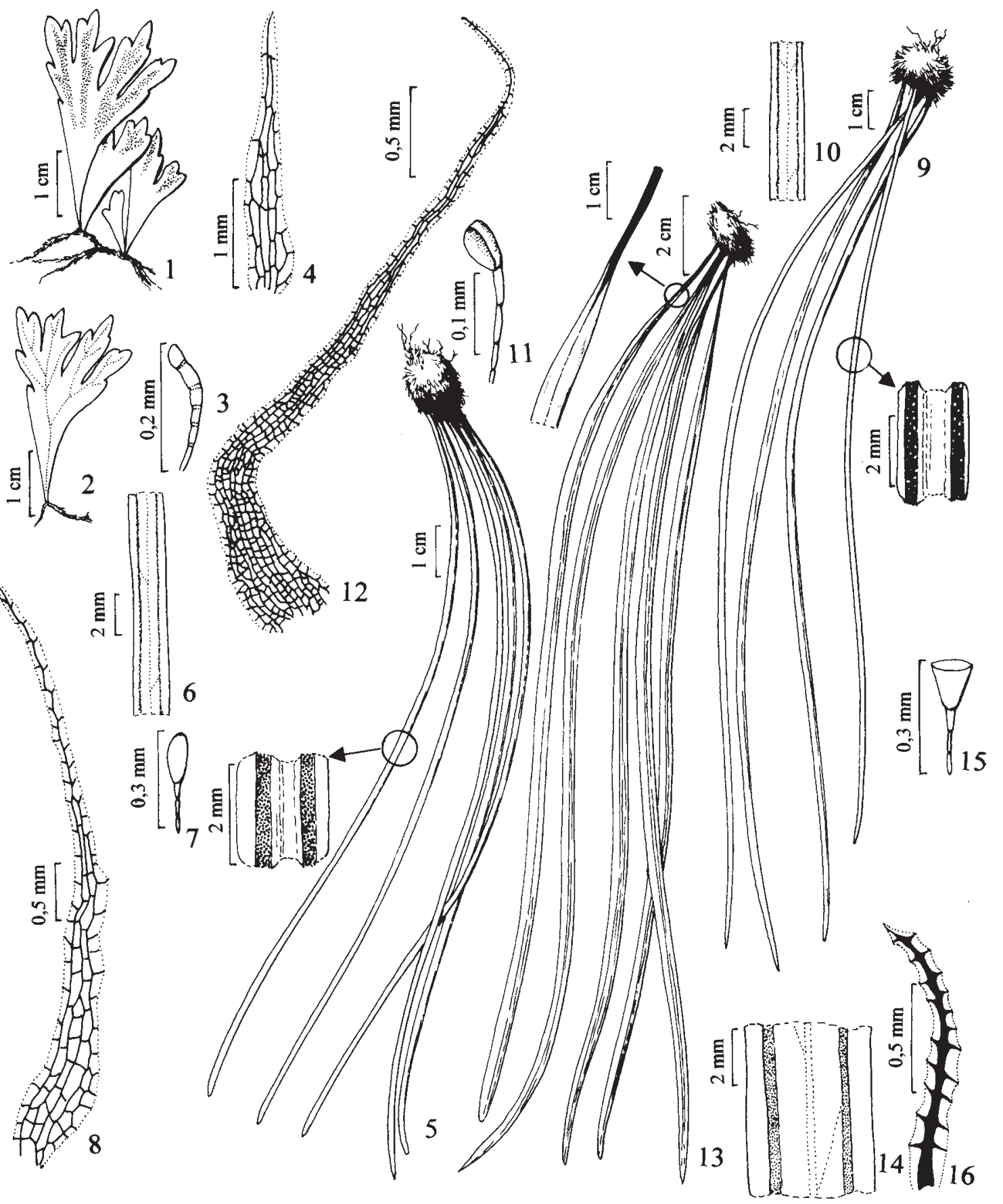

Figuras 17-20. Radiovittaria gardneriana. 17. hábito. 18. detalhe da lâmina fértil e da nervação. 19. paráfise. 20. escama do caule. Figuras 21-23. Polytaenium cajenense. 21. hábito. 22. detalhe da lâmina fértil e da nervação. 23. escama do caule. Figuras 24-26. Polytaenium lineatum. 24. hábito. 25. detalhe da lâmina fértil e da nervação. 26. escama do caule. Figuras 27-29. Polytaenium feei. 27. hábito. 28. detalhe da lâmina fértil e da nervação. 29. escama do caule. Figuras 30-32. Anetium citrifolium. 30. hábito. 31. detalhe da lâmina fértil e da nervação. 32. escama do caule (17-20 - Sylvestre 274; 21-23 - Brade 21326; $24-26$ Nonato 605; 27-29 - Válio 102; 30-32 - Brade 8422).

Figures 17-20. Radiovittaria gardneriana. 17. habit. 18. detail of fertile lamina and venation. 19. paraphysis. 20. stem scale. Figures 21-23. Polytaenium cajenense. 21. habit. 22. detail of fertile lamina and venation. 23. stem scale. Figures 24-26. Polytaenium lineatum. 24. habit. 25. detail of fertile lamina and venation. 26. stem scale. Figures 27-29. Polytaenium feei. 27. habit. 28. detail of fertile lamina and venation. 29. stem scale. Figures 30-32. Anetium citrifolium. 30. habit. 31. detail of fertile lamina and venation. 32. stem scale (17-20 - Sylvestre 274; 21-23 - Brade 21326;24-26 - Nonato 605; 27-29 - Válio 102; 30-32 - Brade 8422). 
a linear-elíptica, estreitada gradualmente em ambas extremidades, membranácea, margens planas ou um pouco revolutas. Nervuras laterais formando 3-5 séries de aréolas entre a costa e a margem da fronde, subparalelas à costa. Esporângios em soros lineares curtos, sobre as nervuras, descontínuos, numerosos, superficiais ou levemente imersos no tecido laminar.

Material selecionado: BRASIL: São Paulo: Ubatuba, próximo à Base Norte, VII-1960, I.M. Válio 102 (SP, SPF); idem, Parque Estadual Ilha Anchieta, 7-VI-2000, V.S. Pereira 42 (SJRP).

Polytaenium feei tem a lâmina longa e muito estreita que gradualmente se afila para o ápice, assim como $P$. lineatum, mas seus soros lineares superficiais não apresentam aletas laterais. Preferencialmente epífita, pode ser também encontrada sobre rochas. Ocorre em florestas pluviais tropicais, sombreadas e úmidas, geralmente em altitudes desde o nível do mar até $700 \mathrm{~m}$.

Esta espécie foi descrita pela primeira vez por Linnaeus (1753) como Hemionitis lanceolata. Com o reconhecimento do gênero Polytaenium, o binômio Polytaenium lanceolatum não pode ser aplicado porque foi primeiramente utilizado por Desvaux (1827), baseado em Vittaria lanceolata Sw., que corresponde a Polytaenium lineatum. Benedict (1911) também utilizou o binômio $P$. lanceolatum baseado em $H$. lanceolata, contudo a publicação de Desvaux (1827) tem precedência e o nome dado por Benedict é ilegítimo. Assim, o nome mais antigo sob o gênero Polytaenium que pode ser aplicado à espécie em questão é $P$. feei, baseado em Antrophytum feei.

Polytaenium feei ocorre no México, América Central, Caribe, Colômbia, Venezuela, Guianas, Equador, Peru, Bolívia e, no Brasil, nos Estados de Pernambuco, Bahia, São Paulo e Santa Catarina, podendo ser considerada "rara" na região de estudo.

Anetium (Kunze) Splitg., Tijdsch. Natuurl. Gesch. Physiol. 7:395. 1840. $\equiv$ Acrostichum sect. Anetium Kunze, Flora 22(1):47. 1839.

Tipo: Anetium citrifolium (L.) Splitg. (三 Acrostichum citrifolium L.)

Anetium é um gênero monoespecífico da América tropical, de ampla distribuição, sendo reconhecido pela organização subacrosticóide dos esporângios. Essa característica, com a especializada arquitetura do esporo, indica evidentemente uma condição derivada na família (Tryon \& Tryon 1982). Segundo Kramer (1990), talvez pudesse ser reunido com Antrophyum.
Na região sudeste, o gênero está representado por:

1. Anetium citrifolium (L.) Splitg., Tijdschr. Natuurl. Gesch. Physiol. 7:395. 1840. $\equiv$ Acrostichum citrifolium L., Sp. pl. 2:1067. 1753. $\equiv$ Antrophyum citrifolium (L.) Fée, Mém. foug. 4:51. 1852. $\equiv$ Hemionitis citrifolia (L.) Hook., Sp. fil. 5:193. 1864. $\equiv$ Pteridanetium citrifolium (L.) Copel., Gen. fil.:224. 1947. Tipo: MARTINICA, Plumier, Traité foug. Amér. t.116. 1705 (lectótipo designado por Tryon, Contr. Gray Herb. 194:225. 1964).

Figuras 30-32.

Plantas epífitas, geralmente pendentes, raramente rupícolas. Caule com dictiostele dissecta, longo-reptante, dorsiventral. Frondes dísticas, espaçadas, sésseis a subsésseis (frondes grandes com um estípite curto). Lâmina 10-100 cm compr., (usualmente 15-30 cm), 3-7 cm larg., inteiras, amplamente elíptica (por vezes estreitadas na base), papirácea a coriácea (podendo ser carnosa quando viva), margens planas ou um pouco revolutas ou ainda onduladas, costa distinta. Nervuras anastomosantes, indistintas a obscuras, formando muitas séries de aréolas entre a costa e a margem da fronde, terminando em pontas livres próximo à margem. Esporângios isolados ou em pequenos agrupamentos espalhados sobre as nervuras e sobre o tecido laminar das aréolas (por vezes mais concentrados sobre as nervuras), superficiais. Paráfises ausentes. Esporos triletes, tetraédrico-globosos.

Material selecionado: BRASIL: São PAULO: Iguape, Boa Vista, Peroupava, VIII-1918, A.C. Brade 7665 (HB); Sete Barras, Fazendas Intervales, Base de Saibadela, Trilha do Quilombo, 21-VII-1994, A. Salino 2017 (BHCB, SJRP); sem município definido: Serra Paranapiacaba, Região do Rio Ribeira, rio Temível, X-1925, A.C. Brade 8422 (HB).

As frondes são suculentas (carnosas a coriáceas) quando novas e os esporângios são facilmente destacados da fronde. Outra característica peculiar desta espécie é o fato de que quanto maior a fronde, maior e mais definido é o estípite.

Anetium citrifolium cresce em florestas pluviais tropicais e equatoriais, do nível do mar até ca. $1.200 \mathrm{~m}$ de altitude. É geralmente epífita, especialmente sobre troncos de palmeiras, e raramente cresce sobre rochas.

Ocorre no México, América Central, Caribe, Colômbia, Venezuela, Guianas, Equador, Peru, Bolívia e, no Brasil, nos Estados do Amazonas, Acre, Pará, Pernambuco, Bahia, Mato Grosso, São Paulo e Santa 
Catarina, podendo ser considerada "rara" para a região de estudo.

\section{Referências bibliográficas}

BAKER, J.G. 1870. Cyatheaceae et Polypodiaceae. In Flora brasiliensis (C.F.P. Martius \& A.G. Eichler, eds.). F. Fleischer, Leipzig, v. 1, pars 2, p.306-624.

BENEDICT, R.C. 1911. The genera of the fern tribe Vittarieae. Their external morphology, venation and relationships. Bulletin of the Torrey Botanical Club 38:153-190.

BENEDICT, R.C. 1914. A revision of the genus Vittaria J.E. Smith. Bulletin of the Torrey Botanical Club 41:391-410.

BRADE, A.C. 1920. Die Farnflora der Umgebung der Stadt São Paulo. Deutscher Verein für Wissenschaft und Kunst, São Paulo 1:39-61.

CHRIST, H. 1900. Spicilegium Pteridologicum AustroBrasiliense. In Plantas novas mineiras (W. Schwacke, ed.). Imprensa Oficial, Cidade de Minas, n.2, p.11-42.

COPELAND, E.B. 1947. Genera filicum, the genera of ferns. Chronica Botanica, Waltham.

CRANE, E.H. 1997. A revised circumscription of the genera of the fern family Vittariaceae. Systematic Botany 22:509-517.

CRANE, E.H., FARRAR, D.R. \& WENDEL, J.F. 1995. Phylogeny of the Vittariaceae: convergent simplification leads to a polyphyletic Vittaria. American Fern Journal 85:283-305.

DESVAUX, A.N. 1827. Prodrome de la famille des Fougères. Mémoires de la Société Linneenne de Paris 6:171-337.

FÉE, A.L.A. 1869. Cryptogames vasculaires du Brésil. BergerLevrault \& Fils, Strasbourg.

FÉE, A.L.A. 1873. Cryptogames vasculaires du Brésil II Partie: Suplément et révision. Berger-Levrault \& Cie., Nancy.

HOLMGREN, P.K., HOLMGREN, N.H. \& BARNETT, L.C. (eds.) 1990. Index Herbariorum. Part I: The herbaria of the world. $8^{\text {th }}$ ed. International Association for Plant Taxonomy/New York Botanical Garden, New York.

KELLOFF, C.L. \& MCKEE, G.S. 1998. A new species of Hecistopteris from Guyana, South America. American Fern Journal 88:155-157.
KRAMER, K.U. 1990. Vittariaceae. In The families and genera of vascular plants (K. Kubitzki, ed.). v. I. In Pteridophytes and Gymnosperms (K.U. Kramer \& P.S. Green, eds.). Springer, Verlag, Berlin, p.272-277.

LINNAEUS, C. 1753. Species Plantarum. v.2. Impensis Laurentii Salvii, Stockholm.

LORSCHEITTER, M.L., ASHRAF, A.R., BUENO, R.M. \& MOSBRUGGER, V. 1998. Pteridophyte spores of Rio Grande do Sul flora, Brazil. Part I. Palaeontographica Abteiling B 246:1-113.

PICHI-SERMOLLI, R.E.G. 1996. Authors of scientific names in Pteridophyta. Royal Botanic Gardens, Kew.

ROSENSTOCK, E. 1904. Beiträge zur Pteridophyten Südbrasiliens. Hedwigia 43:57-167.

SCHAFFER-FEHRE, M. 1996. A preliminary investigation of the paraphyses of Vittaria (Vittariaceae). In Pteridology in perspective (J.M. Camus, M. Gibby \& R.J. Johns, eds.). Royal Botanic Gardens, Kew, p.531-534.

SEHNEM, A. 1967. Vitariáceas. In Flora ilustrada catarinense (R. Reitz, ed.). Herbário Barbosa Rodrigues, Itajaí, p.1-18.

SMITH, A. R. 1995. Vittariaceae. In Flora of the Venezuelan Guyana (J.A. Steyermark, P.E. Berry \& B.K. Holst, eds.). v.2. In Pteridophytes and Spermatophytes: AcanthaceaeArecaceae (P.B. Berry, B.K. Holst \& K. Yatskievych, eds.). Timber Press, Portland, p.327-334.

STOLZE, R.G. 1981. Ferns and fern allies of Guatemala: part II. Polypodiaceae. Fieldiana, Botany, n.s. 6:1-522.

TRYON, R.M. 1964a. Taxonomic fern notes. IV. Some American Vittarioid ferns. Rhodora 66:110-117.

TRYON, R.M. 1964b. The ferns of Peru: Polypodiaceae (Dennstaedtieae to Oleandreae). Contributions of the Gray Herbarium 194:1-253.

TRYON, R.M. \& STOLZE, R.G. 1989. Pteridophyta of Peru: part II. 13. Pteridaceae -15. Dennstaedtiaceae. Fieldiana, Botany, n.s. 22:1-128.

TRYON, R.M. \& TRYON, A.F. 1982. Ferns and allied plants, with special reference to Tropical America. Springer Verlag, New York.

WINDISCH, P.G. 1992. Pteridófitas da região Norte-ocidental do Estado de São Paulo: guia para estudos e excursões. $2^{\mathrm{a}}$ ed. Universidade Estadual Paulista, São José do Rio Preto.

WINDISCH, P.G. \& NONATO, F.R. 1999. Pteridófitas do Estado de Mato Grosso, Brasil: Vittariaceae. Acta Botanica Brasilica 13:291-297. 